Volume 15 - Número 1 - jan/jul de 2020

\title{
O “BRASILEIRO” COMO LÍNGUA DE AFIRMAÇÃO EM PORTUGAL
}

\section{THE "BRAZILIAN" AS A LANGUAGE OF SELF-AFFIRMATION IN PORTUGAL}

\begin{abstract}
Janaina Behling ${ }^{1}$
RESUMO: O presente artigo é fruto de uma investigação desenvolvida num doutoramento na Universidade de Coimbra. Seu tema central é o impacto do português do Brasil, doravante "brasileiro", em espaço português, tema a ser escrutinado por meio de três categorias: o "brasileiro" como língua impossível, o "brasileiro" como língua possível e o "brasileiro" como língua de afirmação em Portugal. Devido não apenas às tradições e contradições históricas e identitárias da língua portuguesa neste país, mas também às reais e imaginárias rupturas materializadas pela linguagem, o artigo se justifica pela necessidade de que sejam estabelecidos engajamentos acerca da percepção de impactos, desafios e perspectivas de uma abordagem transgressiva ao português, uma vez contabilizados diferentes recursos metodológicos de documentação crítica.
\end{abstract}

Palavras-chave: Língua Portuguesa. Língua Brasileira. Pragmática.

ABSTRACT: The present article is the result of a research developed in a $\mathrm{PhD}$ at the University of Coimbra. Its central theme is the impact of Brazilian Portuguese, hereinafter "Brazilian", in Portuguese land, a theme to be scrutinized through three categories: "Brazilian" as an impossible language, "Brazilian" as a possible language and "Brazilian" as a language of affirmation in Portugal. Due not only to Portuguese language historical and identity traditions and contradictions in this country, but also to the real and imaginary ruptures materialized by language, the article is justified by the need to establish engagements regarding the perception of impacts, challenges and perspectives of a transgressive approach to Portuguese, once different methodological resources of critical documentation are taken into account.

Keywords: Portuguese Language. Brazilian Language. Pragmatic.

\section{Introdução}

O português como língua de ciência, língua de prestígio, língua de expansão, língua de unidade nacional, língua de afirmação, língua de tradição, língua falada em cinco continentes, na verdade, não passa de língua como sistema sujeito a falhas. Porque cada uma dessas modalidades, juntas ou separadas, pode e deve significar mais que uma engrenagem de expansão megalolinguística questionável, repleta de contradições, uma vez falada por sujeitos que transformam essa língua continuamente, em função dos espaços históricos em que estão inseridos e que também necessitam de transformação.

A relação entre sujeito, linguagem e sociedade, levando em conta as ideologias que preenchem espaços, é constitutiva dos sentidos, no caso do presente texto, atribuídos ao impacto do português brasileiro em Portugal, numa busca talvez insana pela revisão das bases onde se assentam as necessárias rupturas contemporâneas, de origem especialmente cultural e econômica, em que os brasileiros não podem prescindir de provocar reflexões sobre línguas em contato parcialmente entrelaçadas ou, ainda, sobre o caráter transgressivo de gramáticas distintas quando faladas e escritas em espaço português.

Nesse caso, analisar o português do Brasil, doravante "brasileiro", em Portugal, oferece no mínimo três desafios: compreender por que motivos é impossível enquanto

\footnotetext{
${ }^{1}$ Doutoranda em Linguística do Português pela Universidade de Coimbra. Mestre em Linguística Aplicada pela Unicamp. Licenciada em Letras pela Unesp/Assis. janabehling@gmail.com
} 
Volume 15 - Número 1 - jan/jul de 2020

língua, compreender por que motivos é possível; e compreender por que motivos certa afirmação de ruptura linguística é uma urgência histórica não apenas para migrantes brasileiros em Portugal.

A relação entre linguagem e ideologia, neste texto, destina-se a olhar para o "brasileiro" como língua de afirmação não apenas da relativa (im)possibilidade de (não) ser portuguesa, mas de afirmação dos efeitos de sentido de percepções sobre a língua fora do Brasil e em Portugal em direção a rupturas ideológico-identitárias.

As respectivas percepções de ruptura podem evidenciar, como veremos, desde a inversão de valores de posições-sujeito, expressas em estratégias enviesadas de pronominalização, à penetração do "brasileiro", e não do português europeu, como língua, para outros europeus, por exemplo, em cursos de línguas na Alemanha, revelando os potenciais simbólicos e reais das transgressões.

Ao mesmo tempo, percepções de ruptura podem produzir eventos, como uma tertúlia, constituídos em função não apenas da escuta aperfeiçoada de dificuldades de brasileiros assumirem ou se manterem em postos de trabalhos de mais prestígio em Portugal - no mínimo, compatíveis a elevadas qualificações, vínculos e documentos de acordo com a condição imigrante - mas de quais estratégias se utilizam e os efeitos que produzem na ultrapassagem de subalternizações automatizadas.

A busca dessas percepções se justifica, em último caso, por permitirem atribuir significados aos "brasileiros", as aspas indicam a diversidade de imigrantes vindos do Brasil para Portugal -, enquanto sujeitos discursivos do "brasileiro" - língua portuguesa falada pelos brasileiros -, numa pesquisa científica, atravessados por rotas de legitimação de sua construção sócio-histórica fora do Brasil e, o quanto possível, fora da colonização, fazendo com que seja necessário operacionalizar as escutas e trocas linguísticas interessadas em derreter as bases autoritárias em que se assentam projetos hegemônicos da língua portuguesa.

Sendo assim, o presente artigo se divide em quatro seções, além desta introdução, das considerações finais e das referências bibliográficas: na primeira, exploro o mundo metafórico de Umberto Eco sobre o projeto europeu de busca por uma língua perfeita e a impossibilidade do "brasileiro" ser considerado uma língua, simplesmente, porque o Brasil não fica na Europa. Nessa parte é possível compreender que, se nem o português europeu, sobreposição de sobreposições de outras línguas bárbaras, não faz parte desse projeto perfeito, o "brasileiro" nunca fará parte do imaginário de certa ortodoxia portuguesa e seu sonho (ou pesadelo) de construir sua própria Torre de Babel. Na segunda seção, em linhas gerais, exploro como a crioulização, apesar de ser um termo vasto, mas próprio de uma área da Sociolinguística alinhada a ideologias pós-coloniais, é repleta de contradições como contributo transgressivo, desde o próprio ideal de descrioulização encoberto pelas hierarquias linguísticas brasileiras que, de alguma forma, refletem a rejeição à criolização do português europeu pelos portugueses, por dependerem metodologicamente, nos estudos linguísticos, da estabilidade e homogeneidade "fixas" de grupos sociais. Na terceira seção exploro, para além de algumas pistas, referenciais acadêmico-científicos que simbolizam a textualidade dos movimentos de afirmação do "brasileiro" como língua de ruptura para, afinal, apresentar vantagens teórico-metodológicas de uma abordagem translinguística.

\section{0 "brasileiro" como língua impossível}

A busca da língua perfeita na cultura europeia é uma das obras de Umberto Eco brilhantemente traduzida por Antonio Angonese no Brasil, em 2018. Nesse livro, cuja publicação italiana data de 1993, Eco encaminha sua ficção científica única a uma espécie de história das ideias linguísticas da Europa e suas buscas obstinadas por uma origem 
Volume 15 - Número 1 - jan/jul de 2020

natural, comum a todas as línguas europeias. Essa origem, que emocionante, seria capaz de determinar desde a língua de Adão às minuciosas estruturas de Babel e os seus fantasmas.

Entre as determinações bíblicas da língua perfeita, especialmente resultantes dos confrontos interpretativos de Gênesis 2; 10 e 11, três são imperativas. Primeiro, Deus fala; segundo, fala uma língua europeia e, terceiro, quem compreende as duas premissas anteriores possui um dom ou um estado de graça particular, tanto quanto quem compreende a fala de Deus por meio de raios, trovões e outros fenômenos da Natureza, com letra maiúscula.

A transferência de Natureza para natureza, no caso, é uma forma de ilustrar não apenas os acordos ortográficos mínimos que devem ter sido estabelecidos de milênio a milênio para distinguir criador e criatura, mas as diferentes narrativas fantásticas da criação do mundo, independente de quem acredita ou não na versão bíblica. É uma ilustração destinada a admitir, como Borst (apud ECO, p. 22), que a busca por uma língua perfeita carrega uma ferida exposta, qual seja, a multiplicidade das línguas e, acrescenta-se, dos sentidos que as palavras assumem nessa multiplicidade. Ferida profunda, portanto, porque obriga aos perfeccionistas de plantão admitirem que ela própria, a língua perfeita, não o seja.

Para os gregos do período clássico essa ferida foi relativamente simples de tratar. Aos povos que falavam línguas diferentes da sua chamavam de bàrbaroi, ou seja, "seres que balbuciavam falando de forma incompreensível" (ECO, p. 22). Os estoicos, na sua semiótica articulada, no entanto, "sabiam muito bem que se em grego um determinado som correspondia a uma ideia, aquela ideia, com certeza, estava presente também na mente de um bárbaro". No entanto, como este bárbaro não conhecia a relação entre o som grego e a própria ideia, sua história era no mínimo irrelevante.

Falada pelos próprios patrícios e intelectuais romanos e por quem estava interessado nas atividades do comércio, do tráfico, da diplomacia, bem como na discussão científica e filosófica na ecumene conhecida, o Grego (para desespero de quem não pertenceu às 72 línguas originárias das diferentes combinações de letras e sons do Hebraico, como é o caso do português) torna-se justamente a língua em que são transmitidos os primeiros textos do cristianismo (século III d.C.) e, de borla, a organização pormenorizada dos povos por território, divididos entre os que genuinamente compunham a Torre de Babel, os que passariam gerações sonhando em compor e os que não são nem europeus.

Deve ser por isso que, ao longo de mais de mil e setecentos anos dessa transmissão greco-cristã e incalculáveis melancolias, a sinopse da última edição de Introdução à História do Português, do eminente catedrático português Ivo Castro, apresente o seguinte:

“A língua portuguesa não nasceu ao mesmo tempo em todo o enorme espaço que hoje ocupa, mas num pequeno território do canto noroeste da Península Ibérica, de onde se expandiu na direcção do sul. Foi seu berço a Galécia Magna (que inclui a Galiza actual, parte do norte de Portugal e o ocidente das Astúrias). Não nasceu, como pensavam Alexandre Herculano e Leite de Vasconcelos, no centro de Portugal; não nasceu na Lusitânia, mas mais a norte, num território que vai continuadamente desde a Corunha, no extremo setentrional da Galiza, até à ria de Aveiro e ao vale do rio Vouga, que nela desagua" (CASTRO, 2006).

A Linguística Histórica portuguesa de prestígio, bem como o imaginário português contemporâneo sobre suas origens, é carregada de pelo menos três traços do ideal de perfeição típica europeia: a substituição velada da impossibilidade de rejeitar a multiplicidade das línguas, no seio de seu perfeccionismo, pela necessidade de assumir a quantidade de espaços que explorou, (não nasceu em todo o enorme espaço que hoje ocupa); em seguida, pela descrição minuciosa de pontos cardeais europeus que não deixam dúvidas de que Portugal fica na Europa - como se os próprios portugueses não o soubessem, ou para evitar o risco de que se percam. E, por fim, mas essencialmente, pela ideia de que 
Volume 15 - Número 1 - jan/jul de 2020

seja uma língua "nascida" e não resultante de milenar sobreposição religiosa, política, econômica e cultural de outras línguas bárbaras e respectivas simbologias mais ou menos acachapantes.

Levando em conta o que se vinha dizendo sobre a língua perfeita, é curioso como o potencial megalolinguístico (não nasceu ao mesmo tempo em todo o enorme espaço que hoje ocupa) do português europeu parece querer afirmar que, apesar de não ser uma das línguas de Deus ou de Adão, é uma língua que vive tentando compensar, com quantidades de tempo e espaço fora da Europa, uma sua certa condição mais ou menos desprezível no espaço geopolítico comum europeu.

Assim, embora seja o fragmento relativo a uma sinopse que, não obstante, está atrelada a uma Europa moderna, de fato nascida da dissolução do Império Romano e dos reinos romano-bárbaros, "a conta não fecha", ou seja, a quantidade de falantes ou de territórios longínquos da língua portuguesa, na prática, acaba por trazer vantagem nenhuma para os portugueses, numa Europa arraigada a ideais de ancestralidade e coesão cultivados no imaginário português, especialmente, depois da entrada de Portugal na Comunidade Europeia. A essa altura, 1986, o perfil do imigrante e também da variante "brasileiro" deixam de estar associados a nichos sociais letrados de prestígio, como os de diferentes profissionais liberais (dentistas, publicitários e profissionais da área de informática), que deixaram o Brasil por conta da instabilidade econômica gerada no governo Collor, em anos anteriores, e passam a ser associados, imigrantes e variante da língua, a nichos sociais letrados desprestigiados, como os de trabalhadores da construção civil, do comércio, dos restaurantes e dos serviços domésticos (SCOTT, 2016, p. 31) que viam em Portugal uma chance de enriquecer, diante dos vultuosos incentivos financeiros recebidos pelo país com a adesão ao euro.

É a confusio linguarum, voltando a Eco, que acaba por formatar o pensamento linguístico português em geral sobre seu quinhão nas determinações das línguas divinas, todavia, não como guardiã da multiplicidade de si mesma dentro de uma Portugal pós-UE, mas como engenhoca portadora da capacidade de estabelecer novos mosaicos de uma Babel toda sua longe dali em que, sob o emblema da diferença étnico-linguística, armamse uns contra os outros. Na prática cotidiana das línguas, então, é possível experienciar situações que variam do deleite pelo contato à xenofobia linguística numa mesma conversa, sendo comum ouvir expressões do tipo "fala português" proferidas por portugueses de diferentes nichos sociais, nas situações mais variadas.

Por meio de uma rápida viagem metafórica sobre a obra de Eco, quis demonstrar porque, na cabeça dos portugueses mais arraigados ou ortodoxos sobre sua filiação europeia, o "brasileiro" é impossível enquanto língua, do mesmo modo que os brasileiros, obviamente, são impossíveis enquanto europeus, estando fadados a calarem-se, o português brasileiro e seus usuários, desde a origem, por serem fruto cotidiano de uma tentativa frustrada de compensação do relativo desvalor do próprio português europeu no Velho Continente.

\section{0 "brasileiro" como língua possível}

Alheio a eurocentrismos, fato é que o "brasileiro" arrebenta, fragmenta, lasca, atropela ou simplesmente transgride (FOUCAULT, 1977:33 [1963]) o português europeu em Portugal. A Figura 1 é capaz de ilustrar tal façanha em função de usos eventualmente distópicos de recursos pronominais equativos a formas de tratamento possíveis no Brasil que, não obstante, subvertem hierarquias, por exemplo, nos usos de "presidente", "doutor", "chefia", atribuindo tais nomes a pessoas consideradas pertencentes a nichos sociais considerados de menor prestígio: 
Volume 15 - Número 1 - jan/jul de 2020

Figura 1: Formas de tratamento em "brasileiro

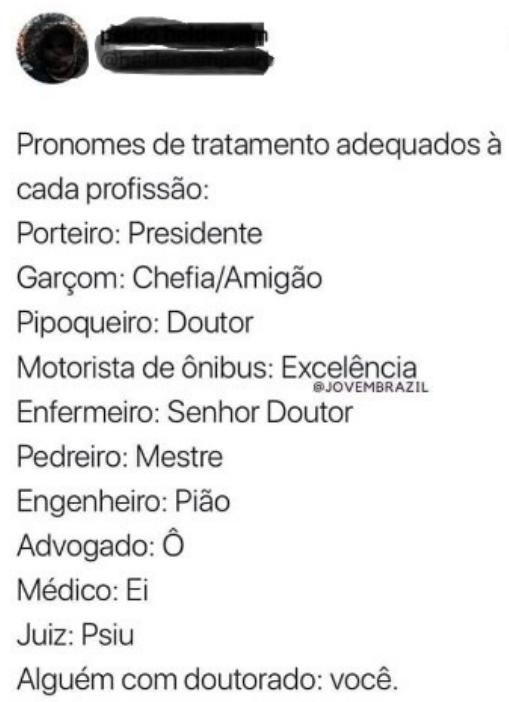

Fonte: Desconhecida

A Figura1, na verdade, é apenas uma pista de como as subversões entre o português e o "brasileiro" podem ser dadas desde um fenômeno relativamente simples como a pronominalização, conforme o uso de nomes que indicam posição de prestígio social são aplicados a pessoas em posição de menor prestígio. No entanto, muitos outros fenômenos foram analisados com muito mais profundidade por especialistas proeminentes, como na publicação do livro Português brasileiro: uma segunda viagem diacrônica (GALVES et al, 2019)

Nesse livro, por exemplo, vão sendo desenhadas as possibilidade de repensar o status do "brasileiro" como pertencente ao grupo dos marginais sintáticos (GALVES apud ROBERTS, 2019), que oportuniza trazer novas possibilidades do contato linguístico para o centro da discussão. Além disso, o livro permite indagar por uma caracterização teórica genuína, na qual esteja incluída, no estudo das percepções do "brasileiro", com propriedade, o aporte às origens africanas e indígenas da língua (AVELAR, 2019), permitindo refletir, afinal, sobre as origens de certos impactos da língua fora do Brasil e, não obstante, atribuir sentido às relativas inversões de valores expressas em sistemas de pronominalização.

Sendo assim, pensando no impacto do "brasileiro" em Portugal em termos práticos, a pronominalização dá visibilidade à inversão de valores identitários de diferentes posições-sujeito (ORLANDI, 2001) marcadas pela relação, no caso, nome/profissão, fenômeno que, em relação ao português europeu, (des)confere prestígio a quem quer que esteja de alguma forma favorável à manutenção do sistema rígido de castas comum às duas culturas linguísticas, a portuguesa e a brasileira.

Nas esferas científicas portuguesas mais fortemente hierarquizadas, os impactos da inversão de valores identitários de diferentes posições-sujeito correspondem a sérios dissabores, por exemplo, ao tratar alguém com doutorado por "você". Em Coimbra, por exemplo, tratar um catedrático por "você", em "brasileiro", muito diferente de selvageria ou caipirismo, em termos pejorativos, dificilmente será considerado justamente uma estratégia de busca por um lugar mais simétrico de posições-sujeito, por si, repleta de consideração e respeito. Porém, para o catedrático, para os próprios colegas ou mesmo para 
Volume 15 - Número 1 - jan/jul de 2020

o porteiro, o atendente de mesa, o pipoqueiro, o enfermeiro, o pedreiro, o engenheiro, o advogado, o médico, o juiz portugueses, é um tratamento facilmente considerado acinte vernacular. Era esse tipo de narrativa que eu ouvia na diretoria do $3^{\circ}$. Ciclo em Linguística do Português da Universidade de Coimbra, cujos últimos festejos de aniversário comemoraram 730 anos.

Entre transgressões, assim como os gregos resolveram os impasses linguísticos da Europa, na visão de Eco, o "brasileiro", desde uma incrível capacidade de contra-ação das leis pronominais canônicas, eventualmente reflete uma maior flexibilidade dos falantes brasileiros para transitarem em diferentes ambientes, não obstante, porque dotados de um certo despojamento (às vezes confundido com inadimplência) no uso de formas de tratamento, capaz de garantir, a variante brasileira, seu próprio espaço na Europa, por exemplo, conforme ilustra a Figura 2, pela oferta de cursos de "brasileiro" para alemães:

\section{Figura 2: O "brasileiro" como língua para outros europeus}

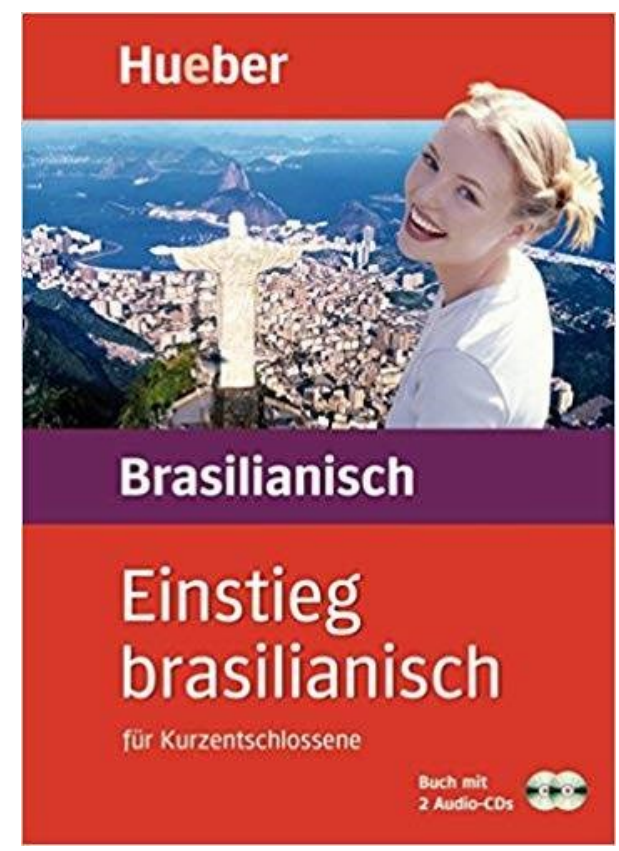

Fonte: https://shop.hueber.de/en/einstieg-brasilianisch-pak.html

As Figuras 1 e 2 são então pistas de que o "brasileiro" pode estar a caminho de uma cisão irreversível em relação ao português europeu e seus porteiros.

O problema da grande massa de brasileiros imigrantes, no entanto, para usar uma expressão de Jervis (apud PENNYCOOK, 2006, p. 74), é que nem mesmo os pronomes atestam uma transgressão reflexiva da língua, ou seja, questionadora de "seu próprio papel e o da cultura que a definiu em sua alteridade".

Esses quetionamentos podem e devem despertar nos brasileiros, especialmente em Portugal, para além das irreverências, uma verdadeira revisão dos papéis e valores identitários impostos pela maior ou menor assimilação de si, não como falantes de uma não-língua, mas como falantes de uma língua capaz de subverter nomes e espaços históricos da subalternização, esta, peça importante de linguísticas hierárquicas fundadoras (PINTO, 2013). Ao mesmo tempo, é justamente a "síndrome de pertencimento" um dos fatores que talvez mais dificulte a transgressão reflexiva necessária ao respeito pelo "brasileiro", primeiro, fora do Brasil e, segundo, em Portugal. 
Volume 15 - Número 1 - jan/jul de 2020

Essa dificuldade reflexiva, em Holm (2004, p. 15), passaria, inevitavelmente, pelo registro e análise de movimentos linguísticos, de um lado, de reconhecimento da reestruturação parcial da língua, a ponto de o português europeu assumir (ou sofrer) cada vez mais influência da linguística brasileira, no caso, a começar pela inversão de posiçõessujeito; por outro, pelo registro de movimentos de descrioulização do português brasileiro, em especial, dados por aqueles que não aceitam a crioulização como fenômeno natural do "brasileiro", apesar de seus potenciais de reversão de papéis históricos de minorização e emudecimento.

O trabalho de linguistas do português, nesse caso, seria justamente identificar, em termos transgressivos, em que contextos e situações, em Portugal, é possível dintinguir o português brasileiro como língua crioula de uma língua totalmente reestruturada, algo que para Holm tem a ver com fenômenos correspondentes a línguas em contato parcialmente entrelaçadas. Todavia, estamos longe de apresentar tais identificações com o devido rigor.

\section{0 "brasileiro" como língua de afirmação em Portugal}

O "brasileiro" necessita ser encarado como língua de afirmação da possibilidade de enfrentamento dos projetos megalolinguísticos de dominação sociocultural, política e econômica de pós-colinialismos que, de fato, como diria Pinto (2013, p. 129) "não pode depender metodologicamente da estabilidade e homogeneidade de grupos sociais", mas sim, do escrutínio e denúncia de subalternizações mais ou menos veladas, pelas quais brasileiros e outros imigrantes são assujeitos, dentro de Portugal, em pleno século XXI.

Entretanto, por mais simplória que seja a afirmação do "brasileiro" como língua de ruptura, em jornais de grande circulação ${ }^{2}$, não deixam dúvidas do profundo incômodo, ou mesmo repúdio, que a ruptura pode gerar para uns e para outros, de modo que falar em "qualidade de vida linguística", termo assinalado no referido jornal e referente à maior qualidade de assesso à esfera pública portuguesa por falantes brasileiros, não passa de uma mera abstração.

Essa abstração sobre qualidade de vida linguística, na verdade, está relacionada a muitas outras, em termos de construção de identidades brasileiras fora do Brasil, que, no entender de Pennycook (2006, p. 68-70), citando Widdowson, estaria atrelada a certas hipocrisias.

Em outras palavras, qualidade de vida linguística é uma abstração quando, por exemplo, é comum que desigualdade, pobreza e racismo existam e sejam expressos pela linguagem, mas que isso nada tenha a ver com interesses de seus especialistas. É uma abastração quando a investigação crítica é acusada de aderir a um tipo de ideologia particular, cujas posições, para terem valor científico, devem ser no mínimo neutras, mesmo que os sentidos a serem atribuídos a tal expressão estejam carregados de tenacidade intelectual. É uma abstração, ainda, quando reduzida a uma etiqueta, ou seja, expressão desmerecida de crédito e, portanto, de engajamento.

Por fim, fato é que qualidade de vida linguística, embora "qualidade de vida" seja uma expressão emprestada da Economia, sequer é assunto corrente em qualquer espaço da Linguística do Português, nos estudos de crioulização ou estudos linguísticos pós-coloniais até o presente momento.

\footnotetext{
2 "Nós falamos "brasileiro". Fonte:https://www.cartacapital.com.br/cultura/nos-falamos-brasileiro-defendedoutoranda-que-pesquisa-o-portugues/. Último acesso: 06.09.2020.
} 
Volume 15 - Número 1 - jan/jul de 2020

\section{Os alquimistas estão chegando?}

"Mas, afinal, que português do Brasil é esse? O que é falado no Pará? O que é falado no Rio Grande do Sul? E que português de Portugal? O que é falado no Minho ou o que é falado nos Açores? O português não é o do Brasil nem o de Portugal; afinal, o português?... O português é de quem o fala!"

Madalena Teixeira em "Estudos da Língua Portuguesa: a União na Diversidade”.

O “angolano", o "moçambicano", o "guinês", o "macauês", o "goano", o "santomês", o "timorês", o "caboverdês", o "damês" ou o "diuês" e todas as supostas línguas portuguesas espalhadas pelo mundo são nomes genéricos, mas como línguas de afirmação são próprias de uma hipótese sustentável por diferentes matizes ideológicos, cuja noção de ruptura é um termo inesgotável em cada um dos contextos talvez pós-geopolíticos da língua portuguesa, de modo que a expressão "o português é de quem o fala" tem impactos muito mais complexos que a construção de um ideal de união na diversidade. Como colaboração mais ou menos emblemática sobre o assunto, destaco a importância de abordagens indisciplinares de linguistas aplicados (MOITA LOPES et al, 2006; 2013), dos estudos funcionalistas (NEVES, 2017) e enciclopédicos (ORLANDI, s/d) na era de uma globalização (KUMARAVADIVELU, 2006) de movimentos transcontextuais (BLOMMAERT, 2010; 2011) e de alguma sociolinguística experimental brasileira (FREITAG, 2016) como dispositivo de reflexão dessa complexidade.

No entanto, as referências sobre uma suposta língua brasileira não parecem suficientes no trabalho de percepção linguística de seus falantes fora do Brasil, ou pelo menos, investigações afins não podem prescindir de outros pareceres científicos produzidos em Portugal, em especial, pareceres e interações articuladas por brasileiros neste país junto aos portugueses, impreterivelmente. Por outro lado, o que parece estar sendo configurado para tais investigações é a necessidade de uma abordagem translinguística da língua portuguesa, sendo preciso selecionar os que já estão em direção a algum tipo de ruptura, seja política, social ou cultural.

Entre as pesquisas relacionadas a brasileiros em Portugal desenvolvidas por brasileiros, destaco a tese de Minga (2019), intitulada A Construção do Outro na Opinião Pública: representações contemporâneas do Brasil e dos brasileiros na sociedade portuguesa, defendida na Universidade Nova de Lisboa. Entre outros objetivos da investigação, Minga destaca que

\footnotetext{
"Após a análise ao discurso jornalístico, dinamizámos alguns grupos de foco e entrevistas a imigrantes "brasileiro"s (alguns deles com posição de liderança na comunidade) com presença em Portugal anterior a 2009 , tendo por objetivo não apenas verificar a validade das conclusões anteriormente estabelecidas, mas sobretudo compreender de forma mais abrangente como estas pessoas percecionam a evolução das representações sociais sobre si mesmas e o seu país, presentes nos media e na vida quotidiana, a nível da interação direta com os portugueses". (MINGA, 2019, p1.Grifos meus).
}

Ela encontrou, em sua tese, um modo de articular percepções discursivas que circulam na imprensa portuguesa, validadas ou não por brasileiros residentes em Portugal há mais de 10 anos, inclusive, líderes. Entretanto, seu texto é híbrido, repleto de marcas do português europeu (dinamizámos, no lugar de dinamizamos, percecionam, no lugar de percebem), mostrando que a esfera científico-acadêmica, como esfera de contato, ainda é de contenção de hibridismos como transformação histórica de práticas discursivas contrahegemônicas (BHABHA, 2003), de modo que uma tese em "brasileiro", em Portugal às vezes, parece uma espécie de crime que merece castigo: 
Volume 15 - Número 1 - jan/jul de 2020

Figura 3: $O$ despreparo de universidades portuguesas também para brasileiros

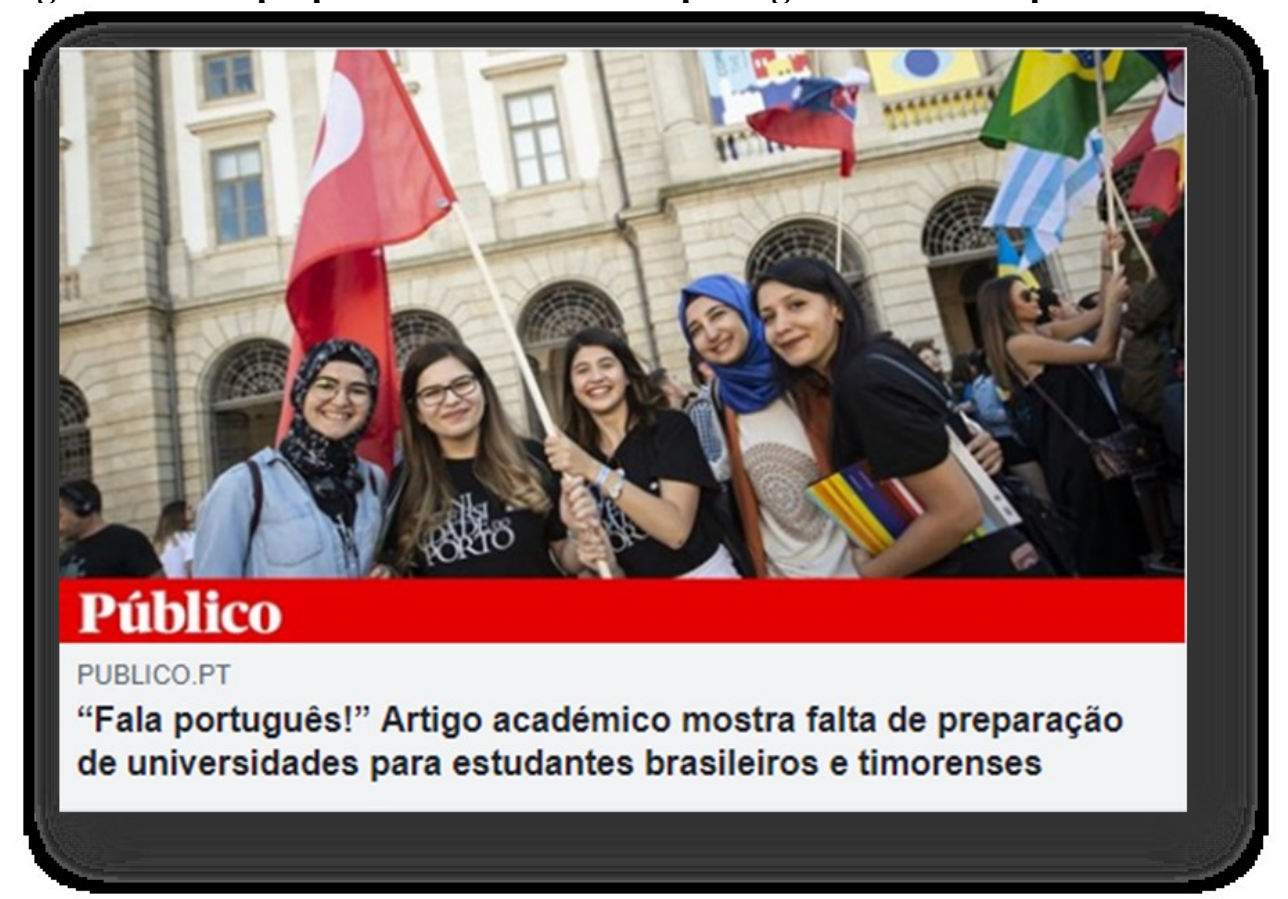

Fonte: https://bit.ly/326PBtE

Já no campo da Sociolinguística portuguesa recente e dos estudos das migrações em Portugal, Keating (2013, 2019a, 2019b, entre outros) é uma referência interessante para tratar de rupturas com assiduidade, por não deixar perder de vista o próprio "estatuto intermédio da língua portuguesa no espaço geopolítico europeu, agindo simultaneamente como língua de estrutura (língua nacional, oficial, institucional) e como língua de acção (de minorias migrantes e como língua franca)"( KEATING et al, 2013, p. 221), mas de forma não limitada a essas duas categorias, estrutural e ativa, por movimentar conceitos hegemônicos de língua, enquanto usuários do português agem em dinâmicas de mobilidade e criatividade em diferentes espaços.

Em outras palavras, é provável que Keating esteja se aproximando do devido rigor na identificação de fenômenos correspondentes a línguas de contato preconizado por Holm (2004), em que a então "síndrome de pertencimento" é relativizada de acordo com a esfera em que a língua portuguesa, cada vez mais diversa ou multifacetada, é utilizada no espaço geopolítico português. Ao mesmo tempo, fica em aberto como assimilar as transgressões cotidianas em direção a mais qualidade de vida linguística quando, por exemplo, o próprio português europeu normativo e seus especialistas não podem prescindir de registrar e indexar as mudanças "sofridas" pela língua. Essas mudanças são mais facilmente registradas em movimentos linguísticos menos fortemente institucionalizados que, todavia, colocam em suspensão a ideia de "língua nacional", daí a necessidade de movimentar conceitos hegemônicos de língua a partir do uso. Nesse caso, estaria também o português europeu, assim como o "brasileiro" e como qualquer outra língua, de um lado, sujeito ao reconhecimento de sua contínua reestruturação e, de outro, de assimilação de sua própria diversidade, no caso, pós-colonial.

Além de contribuir para perceber o português europeu de forma multi-situada na Europa, ou fora de seus condomínios, Keating (2019b, p. 1) propõe conjecturas sobre o conceito de literacy-in-action, no qual o português (europeu) não pode prescindir da "necessidade de seguir trajetórias dos discursos de linguagem e letramento à medida que se cruzam com outros discursos relacionados a classe, raça, etnia ou nação", propondo uma 
Volume 15 - Número 1 - jan/jul de 2020

abordagem histórica, ecológica e material da língua em contextos multilíngues de língua portuguesa ${ }^{3}$.

Keating leva em consideração as agruras e ortodoxias reforçadas por uma Portugal recém saída do Estado Novo, evidentemente, bastante afeita ao espírito eurocêntricocolonizador e propõe pesquisas mais colaborativas, de escuta e participação menos automatizadas de percepção da língua face os processos de significação da própria língua enquanto policêntrica, ou talvez, poli-valente.

Esse tipo de abordagem, focada em literacias/letramentos,, permite indagar sobre como estão determinados não apenas os brasileiros, mas também outros falantes de algum tipo de língua portuguesa, pelas diferentes formações discursivas em que são inscritos em Portugal. Ou como, a partir dessa inscrição, ainda que de forma intermitente, o "brasileiro" é carregado de transformação histórica de práticas discursivas que proponham "uma ressocialização significativa, internalizada, [talvez] duradoura e incorporada em um novo ambiente linguístico" (KEATING, 2019b, p.1), tentando discutir em que medida as disposições e recursos da pesquisa biográfica contribuem para capturar a natureza biopolítica de uma linguagem que na verdade não é muda, é emudecida.

Pensar uma abordagem translinguística em Portugal, então, tem a ver com uma proposta de transformação discursiva "do brasileiro", seja como sujeito ou como variante da língua, capaz de propor ressocializações significativas, de conquista de espaços portugueses, com qualidade de vida linguística, que transponham a subalternidade automatizada a diferentes mudezas.

Nesse caso, tanto o trabalho de Minga, na atualização contemporânea de identidades brasileiras em Portugal, indexadas (GOFFMAN, 1977) por seus líderes, ainda que materializada numa tese aportuguesada, somado ao trabalho de Keating, na relativa busca pela inovação epistemológica transformadora, constituem pontos de partida de uma investigação sociolinguística fertilíssima que talvez se pode realizar em Portugal, a partir de um manancial de possibilidades metodológicas, em especial, de cunho etnográfico.

\subsection{A documentação de arquivos efêmeros}

$\mathrm{Na}$ introdução do presente artigo penso que tenha explicitado, em outras palavras, que a (des)crioulização como contributo transgressivo é repleta de contradições, uma vez que, entre hierarquias linguísticas, encobre os reflexos de uns e de outros na homogeinização de grupos linguísticos. Retomo a colocação para ilustrar como essa cobertura é também atropelada natural e cotidianamente em Portugal, independente de atravessamentos brasileiros, a partir do caráter transgressivo natural às artes na manifestação de resistências (GALLO, 2017), como no caso da Figura 4, focadas na manipulação da identidade (GOFFMAN, 1983) como recurso de desestabilização de ícones literários, ou celebridades portuguesas de projeção "sagrada" e internacional:

\footnotetext{
${ }^{3}$ Do original: "I point to the need to follow trajectories of language and literacy discourses as they intersect with other discourses related to class, race, ethnicity or nation and I propose a historical, ecological and material approach to literacy-in-action in multilingual Portuguese speaking contexts, an approach which would be based on multi-sited collaborative research". Tradução livre.
} 
Volume 15 - Número 1 - jan/jul de 2020

\section{Figura 4: peça performativa de deteriorização de ícones globais}

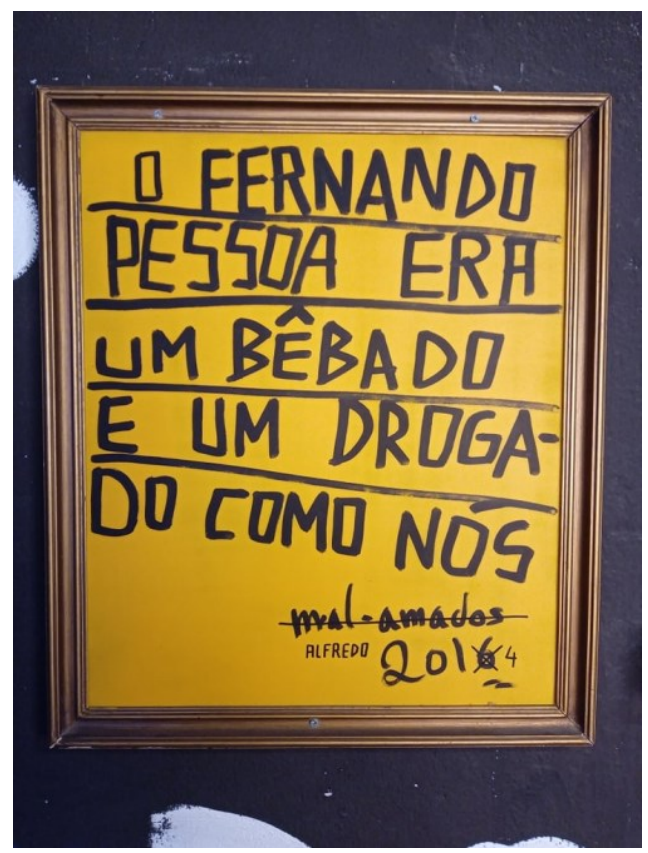

Fonte: A autora (2019)

Uma peça performativa seria qualquer coisa relacionada à documentação de arquivos subjetivos (BEHLING, J.; BLANCO, M.; SARAIVA, C., a sair) ou efềmeros, que permitam localizar o papel das artes performativas, eventualmente mais preparadas para os desmanches transgressivos propostos tanto pela língua brasileira, a priori não reflexiva, quanto pelos diferentes recursos ou gêneros discursivos que sirvam de reajuste identitário da língua e dos falantes de algum tipo de português em Portugal. A noção de espaço é constantemente ressignificada, de fato, em eventos de letramentos dos mais variados (BEHLING, 2018), cotidianos e não necessariamente legados a esferas educativas, como as academias $\mathrm{O}$ que não se pode perder de vista é a capacidade de falantes e falares de diferentes "línguas em português" estarem implicadas na faculdade de se articularem acerca dessa língua entre ordens de indexicalidade (SILVERSTEIN, 2003), em que os usuários da língua indexam outros mundos em seu próprio, como mixagens expressas na linguagem.

Os métodos de documentação de arquivos vivos ou efềmeros são o confronto entre descrição e interpretação de objetos simbólicos do não-dito na produção discursiva, produtores de efeitos metafóricos ou deslizamentos de uma formação discursiva para outra, que afeta o sentido das palavras no espaço e do próprio espaço português

Um desses métodos é a metáfora, relativa ao deslocamento dos sentidos mais ou menos cristalizados pelas tradições e imaginários identitários de brasileiros e portugueses, entre perspectivas livres de rótulos. É exigida à documentação de arquivos vivos a maior capacidade de escuta, não ingênua, capaz de duvidar das grandes certezas sobre o português e sobre os portugueses em Portugal. É necessário, também, saber observar, descrever e impactar as conjunturas ecológicas em que se dá essa escuta, buscando compreender como os sujeitos significam aos outros e a si mesmos, sobretudo, para falar e ouvir-se sobre a língua.

Nesse caso, investigações sociolinguísticas do "brasileiro" em Portugal não fazem de seus investigadores recipientes que precisam ser preenchidos de cultura europeia 
Volume 15 - Número 1 - jan/jul de 2020

para falar ou pesquisar português, ou ser obrigado pela erudição a conhecer Fernando Pessoa, por exemplo, um homem comum, que faz coisa de gente comum. Brasileiros e demais colaboradores de trangressões linguísticas em português são produtores polivalentes de elementos científicos de (re)conhecimento, então, do impacto de gêneros discursivos muito variados que exigem oralidade, leitura e escrita como atividades redimensionadas.

Duas atividades que assumi e desenvolvi como investigadora independente em Portugal, ou seja, sem apoio institucional, apesar do vínculo com a Universidade de Coimbra como doutoranda, já foram realizadas como piloto desse tipo de ação. Uma delas foi uma oficina de escrita criativa, na qual a escrita de autobiografias apresentou a multiplicidade de textualidades de histórias de vida, tendo como dispositivo, de acordo com a proposta, a busca por palavras guardadas na memória e que se tornaram marcantes. Assim, da crônica à poesia, passando por mini-contos fantásticos, os textos apresentaram alguns confrontos com a língua portuguesa, desde a caracterização dos e das participantes como usuários do português até a consideração sobre usos abandonados no tempo, por exemplo, em relação à palavra "subúrbia" e "misericórdia".

Outra atividade foi uma Tertúlia, realizada na Casa do Brasil, em Lisboa. Como uma roda de conversa típica de espaços simétricos, os e as participantes, não apenas portugueses e brasileiros, mas outros imigrantes radicados em Portugal há anos, escreveram relatos de experiências. Dessa atividade destaco um relato de discriminação laboral, de uma advogada brasileira, pós-graduada e com anos de experiência no Brasil, mas inferiorizada pelo português utilizado na produção da ecologia de gêneros discursivos que povoa seu cotidiano em Portugal. Enquanto documentação crítica, as autobiografias e os relatos de experiência permitiram reflexões sobre a língua que, por um lado, derretem a estabilidade de gêneros autobiográficos e, por outro, acusam tensões embutidas na completa falta de senso prático, no mínimo, à multiplicidade do português na contemporaneidade portuguesa.

Há, ainda, cerca de 30 horas de conversas espontâneas gravadas de forma mais ou menos aleatória, nas quais o projeto de reflexão sobre a língua se materializa de forma efềmera, ou seja, entre assuntos muito variados, que acabam por impulsionar autorreflexões, creio, especialmente porque as gravações acabam muito mais circunscritas, salvo algumas exceções, à esfera acadêmica de Coimbra. Entretanto, até o presente momento, estas atividades independentes não surtiram efeito científico à catedra.

Um grande desafio dessas intervenções é alcançar resultados de mudança, primeiro, nos espaços de escuta e empoderamento linguístico, indiscriminadamente, em direção à multiplicidade da língua e registro sistêmico de trangressões na própria materialidade da linguagem. Em seguida, ou concomitantemente, alcançar resultdos na transformação de costumes e contenção de violências institucionalizadas mais ou menos insuspeitáveis, simbólicas e práticas. Porque é preciso criar mecanismos de deteriorização de hierarquias em que todos e todas possam se envolver, indiscriminadamente, na relação entre linguagem e ideologia em Portugal neste século vinte e um, de modo que o "brasileiro" sirva como dispositivo de diálogo investigativo crítico. Há muito trabalho a ser feito.

Outro desafio, com o qual tenho particularmente lidado há pouco mais de uma década, é validar a ação de linguistas aplicados em diferentes áreas profissionais problematizando as relações quase indissolúveis entre letramento (literacia) e espaço, como já afirmei, um conceito constantemente ressignificado. Uma vez não ressignificado o conceito de espaço a cada intervenção ou evento de letramento, o par ordenado ensinoaprendizagem, a meu ver, literalmente coloniza todo o espaço como sendo educativo, fazendo da Educação uma máquina de moer a tal da qualidade de vida linguística, moendo 
Volume 15 - Número 1 - jan/jul de 2020

os gêneros discursivos que a sustêm ou, como talvez assinalasse Signorini (1998:2001) de moer identidades.

Havendo condições, posso retomar esse percurso de validação que, não obstante, sob orientação, teria como pano de fundo uma certa proposta de desmantelar a língua portugusa em Portugal, sempre buscando interlocução estrangeira, criando linhas de fuga de documentação crítica, entre eventos orais e escritos, para que os e as interlocutores/as possam, em último caso, assumir em liberdade seus próprios percursos de engajamento linguístico na vida ordinária institucionalizada, o quanto possível, para além de eurocentrismos, quem sabe, a começar pelas esferas acadêmicas pelas quais transito e pertenço.

\section{Considerações em aberto}

O presente artigo é fruto de sistematizações iniciais e percepções desenvolvidas no âmbito de um doutoramento em Linguística do Português na Universidade de Coimbra, a propósito dos impactos do português do Brasil, ou "brasileiro", em espaço português, tema que tentei escrutinar, neste momento, por meio de três categorias efêmeras: 0 "brasileiro" como língua impossível, o "brasileiro" como língua possível e o "brasileiro" como língua de afirmação em Portugal. O sentido de efemeridade tem a ver com a documentação, sempre inacabada, das tradições e contradições históricas e identitárias da língua neste país e, também, às reais e imaginárias rupturas materializadas na e pela língua portuguesa.

Considerando que as tradições eurocêntricas de pertencimento do português europeu, ao imaginário de uma língua perfeita, é ao mesmo tempo causa e sintoma da rejeição ao brasileiro como língua e, portanto, rejeição a seus falantes, apresentei o "brasileiro" como língua impossível não apenas em Portugal, mas no imaginário de quaisquer falantes mais ou menos afeitos a este ideal de pertencimento. A questão é que, na configuração de posições-sujeito, entre estratégias de pronominalização, por exemplo, a língua brasileira transgride o português europeu, a ponto de servir produtos e serviços a outros europeus como referencial autônomo de língua.

Esse tipo de questão indaga por explorar os desafios e busca por perspectivas de sustentação de uma abordagem translinguística da língua, capaz de propor e promover reflexões sobre rupturas ideológicas necessárias aos próprios brasileiros, indiscriminadamente, em direção à transformação de costumes, prevenção e contenção de violências simbólicas e práticas.

Entre os diferentes recursos teórico-práticos contabilizados para que tal abordagem seja clara, entendo que não é possível prescindir de manifestações históricas situadas e contextualizadas, para as quais a Linguística Histórica portuguesa e os estudos vernaculares da língua brasileira são insuficientes.

Outros recursos, especialmente produzidos em Portugal, dentro e fora da esfera científico-acadêmica, mostram como a percepção do "brasileiro" é latente, primeiro, quando são brevemente destacados discursos sobre falantes e falares em Portugal, sem perder de vista que há trabalhos científicos sobre se e como discursos sobre brasileiros são validados ou não por lideranças brasileiras. Em seguida, quando espaços universitários de literacy-in-action são criados, nos quais o português, de modo geral, é exposto a uma abordagem histórica, ecológica e material da língua em contextos multilíngues, em último caso, capazes de indexar rupturas em direção a mais qualidade de vida linguística em Portugal e os necessários transbordamentos sociais, econômicos, culturais institucionalizados. 
Volume 15 - Número 1 - jan/jul de 2020

A documentação crítica seria, então, um recurso suplementar, igualmente amparado pelas esferas científicas correspondentes, cuja noção de efemeridade assuma sua condição transitiva entre a academia e "a vida real" na construção de um corpus proveniente dessa abordagem ecológica, sempre em movimento, inacabada, cujas amostras revelem perspectivas de otimização de debates multilingues e polivalentes, sobretudo, que considerem o caráter transgressivo da língua para corpos biopolitizados em Portugal.

\section{Referências}

AVELAR, J. Sobre o papel do contato linguístico nas origens do português "brasileiro". In: GALVES, C.; KATO, M.; ROBERTS, I. Português brasileiro: uma segunda viagem diacrônica. Campinas: Editora da Unicamp, 2019.

BHABHA, H. K. O local da cultura. Belo Horizonte: UFMG, 2003.

BEHLING, J.; BLANCO, M.; SARAIVA, C. Linha de Fuga 2018: Documentação e práticas de arquivo subjetivas num Laboratório de artes performativas. Coimbra University Press, 2020.

BEHLING, J. Letramento e Espaço. In.: Entrelaçamentos discursivos. Curitiba: CVN, 2018.

BLOMMAERT, J. and Dong, J. Language and Movement in Space. In.: N. Coupland (ed) The Handbook of Language and Globalization. Oxford, UK: Wiley- Blackwell, 2010. BLOMMAERT, J. Pragmatics and Discourse. In.: The Cambridge Handbook of Sociolinguistics. Cambridge University Press, 2011.

CASTRO, I. Introdução à História do Português. $2^{\mathrm{a}}$ edição revista e muito ampliada. Lisboa: Edições Colibri, 2006.

ECO, U. Em busca da língua perfeita na cultura europeia. Tradução de Antonio Angonese. São Paulo: Unesp, 2018.

FOUCAULT. M. Language, Counter-Memory, Practice. Ithaca: Cornell University Press, 1977 [1963].

FREITAG, R.M.K. Sociolinguística do/no Brasil. Campinas: Caderno de Estudos Linguístico, No. 583. Ano: 2016.

GALLO, S. Biopolítica e subjetividade: resistência? Educar em Revista, Curitiba, Brasil, n. 66, p. 77-94, out./dez. 2017.

GALVES, C.; KATO, M.; ROBERTS, I. Português "brasileiro": uma segunda viagem diacrônica. Campinas: Editora da Unicamp, 2019.

GOFFMAN, E. Estigma: notas sobre a manipulação da identidade deteriorada. Rio de Janeiro: Zahar, 1983.

HOLM, J. Languages in Contact. The Partial Restructuring of Vernaculars. Cambridge University Press, 2004.

KEATING, C. (2019a). Discourses about language and literacy education in Portugal: Past and present. In: Marilyn Martin-Jones \& Izabel Magalhães (eds.), Literacy in the study of social change (Special issue. International Journal of the Sociology of Language. Vol. 5. N. 259).

KEATING, C. (2016:2019b). Biographizing migrant experience. In: International Journal of Sociology of Language. 257:49-76.

KEATING, Clara; Solovova, Olga; Barradas, Olga (2013). Políticas de língua, multilinguismos e migrações: para uma reflexão policêntrica sobre os valores do português no espaço europeu. In: Moita Lopes, Luiz Paulo (org.). Português no século XXI: cenário geopolítico e sociolinguístico. São Paulo: Parábola Editorial, 219-248. 
Volume 15 - Número 1 - jan/jul de 2020

KUMARAVADIVELU, B. A Linguística Aplicada na era da globalização. In.: Por uma Linguística Aplicada Indisciplinar. São Paulo: Parábola, 2006.

MINGA, E.A.P. A Construção do Outro na Opinião Pública: representações contemporâneas do Brasil e dos "brasileiro"s na sociedade portuguesa. Tese de Doutorado. Universidade Nova de Lisboa, 2019.

MOITA LOPES, L.P. (org.). Por uma Linguística Aplicada Indisciplinar. São Paulo: Parábola, 2006.

NEVES, M. H. M. The interface syntax, semantics and pragmatics in functionalism. DELTA. Documentação de Estudos em Linguística Teórica e Aplicada (Online), v. 33, p. 25-43, 2017.

ORLANDI, E, P. Análise de Discurso: princípios e procedimentos. São Paulo: Pontes, 2001.

ORLANDI, E.P. Língua brasileira. Fonte: https://bit.ly/2xZpvfM . Acesso em: 01.01.2020.

PENNYCOOK, A. Uma Linguística Aplicada transgressiva. In.: Por uma Linguística Aplicada Indisciplinar. São Paulo: Parábola, 2006.

PINTO, J.P. Prefiguração identitária e hierarquias linguísticas na invenção do português. In.: O português no século XXI. Cenário geopolítico e sociolinguístico. Organização de Luiz P.M. Lopes. São Paulo: Parábola, 2013.

ROBERTS, I. Gramáticas "marginais" e mudanças sintáticas "extremas": o inglês e o português brasileiro. In: GALVES, C.; KATO, M.; ROBERTS, I. Português "brasileiro": uma segunda viagem diacrônica. Campinas: Editora da Unicamp, 2019.

SCOTT, A.S. Os portugueses. São Paulo: Contexto, 2016.

SIGNORINI, I. (Des)construindo bordas e fronteiras: letramento e identidade social. In.: Lingua(gem) e identidade. São Paulo: Mercado das Letras, 2001. 2a . reimpressão.

SILVERSTEIN, M. Indexical order and the dialectics of sociolinguistic life. Chicago: Pergamon, 2003.

TEIXEIRA, M. (org.). Nota Introdutória. In.: Estudos da língua portuguesa: a união na diversidade. Instituto Politécnico de Santarém: Santarém, 2019.

Submetido em 08/05/20

Aceito em 12/07/20 